\title{
Designing and managing Organizational Interoperability with organizational capabilities and roadmaps
}

\author{
Philippe RAUFFET, Catherine DA CUNHA, Alain BERNARD \\ IRCCyN, Ecole Centrale Nantes, France \\ philippe.rauffet@irccyn.ec-nantes.fr, catherine.da-cunha@irccyn.ec-nantes.fr, \\ alain.bernard@irccyn.ec-nantes.fr
}

\begin{abstract}
This paper discusses organizational interoperability issues in through the study of two cases. Then it presents a framework which can help to design and manage this interoperability, by driving the development of "organizational capabilities".
\end{abstract}

\section{Introduction}

Companies are nowadays dynamic structures, which are rearranged on a regular basis depending on projects and alliances. Organizations become therefore multi-functional, multi-products, or geographically distributed. These reconfigurations have significant consequences in terms of performance at all levels, and they sometimes trigger such an organizational heterogeneity. Organizational interoperability is therefore a key challenge for companies so as to make their resources (sites, people, products, software...) work together, with the same practices and the same processes.

ATHENA defines interoperability as "the ability of two or more systems or components to exchange information and to use [without any misinterpretation or loss of sense] the information that has been exchanged" [1].

As this definition emphasizes, interoperability is only concerned with communication and information sharing so as to make interactions possible. By contrast enterprise integration is broader and is related to cooperation and coordination of the organizational entities and their interactions [2]. However, Vernadat shows that these two notions are linked, since interoperability is a key for supporting enterprise integration. Thus it is essential to make systems interoperable and interacting in order to control and manage complex organizations and drive their performance.
In order to reach this interoperability, enterprises must limit "heterogeneity" [3]. Heterogeneity can be differentiated in three types:

- a semantic heterogeneity, composed of syntax and language problems (signification of speech, sense of the knowledge which can be proceeded and manipulated in the enterprise). That comes from the fact that systems are defined, built and used by different people, in different places at different times, with different aims, with different vocabularies.

- an organizational (or functional) heterogeneity, caused by the differences in practices and business processes. Indeed, different enterprises or departments are growing and developing their own organization isolated from another. Consequently, same tasks may not be processed in the same way in two different organizational units and problems can occur at their cooperation border.

- a technical (or material) heterogeneity, resulting from the use of several materials to transport, transmit, and operate information which are not compatible.

This paper only focuses on organizational interoperability. It deals with some current works fulfilled in the ANR project Pilot2.0 [4] around a system managing organizational capabilities and named 5 steps ${ }^{\circledR}$ [5]. Section 2 deals with organizational interoperability issues in two different cases. Section 3 discusses on approaches to design interoperability. Section 4 presents the key concept (organizational capability [6]) and the mechanisms of 5 steps ${ }^{\circledR}$, and shows how they could be used among other things to increase interoperability between heterogeneous organizational units and communication between functional and operational people. Finally, limits and perspectives are discussed in last section. 


\section{Organizational interoperability issues in a globalized industrial group and in a French public administration}

The following part deals with two different case studies, Valeo group and General Council of Vaucluse. These two organizations are members of the research Pilot2.0 project, supported by the French National Research Agency (ANR).

The exchanges with these project partners enabled us to analyze their organizational context and to identify their interoperability issues. The summary of this analysis is given in Fig.1.

These two organizations differ in their missions, their organizational structure and their environment. However, they present some common problems:

- There are some difficulties for limiting heterogeneity in functional practices and processes;

- Communication and interactions are rough to animate between different actors (functional with operational people, new sites with elder sites, functional domain with another one, internal services with suppliers and associations...);

- Finally, there is a missing means to manage heterogeneous, complex (multi -products or -services, multifunctional), and extended structures.

From this analysis and these exchanges emerged some levers for overcoming these interoperability issues:

- It is necessary to gather and capitalize local innovations (good practices capture)

- These practices must be deployed broadly, whatever culture and maturity of sites (best practices modeling and deployment)

- Finally, a tool to manage the modeling and the diffusion of these practices is required.

This short view of two different cases enables to characterize organizational interoperability problems met by enterprises and administration. The next section focuses on approach to solve these problems and increase interoperability.

\begin{tabular}{|c|c|c|c|c|c|}
\hline \multicolumn{3}{|c|}{ VALEO } & \multicolumn{3}{|c|}{ General Council of Vaucluse (CG84) } \\
\hline Organization & Environment & Mission & Organization & Environment & Mission \\
\hline \multicolumn{3}{|c|}{ Context } & \multicolumn{3}{|c|}{ Context } \\
\hline 134 plants & \multirow{3}{*}{$\begin{array}{l}\text { Global and } \\
\text { competitive market } \\
\text { (automotive sector) }\end{array}$} & \multirow{3}{*}{$\begin{array}{l}\text { Ensuring customer } \\
\text { satisfaction by delivering } \\
\text { same products with same } \\
\text { quality level }\end{array}$} & $\begin{array}{l}\text { Repartition of services on } \\
\text { administrative territory }\end{array}$ & \multirow{3}{*}{$\begin{array}{l}\text { Collaboration with } \\
\text { other dministrative } \\
\text { entities, with } \\
\text { external suppliers } \\
\text { and associations }\end{array}$} & \multirow{3}{*}{$\begin{array}{l}\text { Ensuring public services on the whole } \\
\text { territory by federating the } 6 \text { domains } \\
\text { (education, social action, civil } \\
\text { engineering, health, public } \\
\text { transportation, project investment) }\end{array}$} \\
\hline \multirow{2}{*}{$\begin{array}{l}12 \text { product branches } \\
15 \text { functional } \\
\text { networks }\end{array}$} & & & 6 services offering & & \\
\hline & & & 26 functional networks & & \\
\hline \multicolumn{3}{|c|}{ Observations } & \multicolumn{3}{|c|}{ Observations } \\
\hline $\begin{array}{l}\text { Difference of seniority } \\
\text { and culture between } \\
\text { plants }\end{array}$ & \multirow{3}{*}{$\begin{array}{l}\text { Plants acquisition and } \\
\text { transfer, new } \\
\text { partnerships }\end{array}$} & Ageing of methods & $\begin{array}{l}\text { Different ways of working } \\
\text { depending on functional } \\
\text { culture }\end{array}$ & \multirow{3}{*}{$\begin{array}{l}\text { Complex connections } \\
\text { with different social } \\
\text { and external actors }\end{array}$} & $\begin{array}{l}\text { Difficult strategic alignment of the } 6 \\
\text { service domains }\end{array}$ \\
\hline \multirow{2}{*}{$\begin{array}{l}\text { matrix structure with } \\
\text { operational and } \\
\text { functional people }\end{array}$} & & $\begin{array}{l}\text { Differences of maturity } \\
\text { between plants }\end{array}$ & \multirow{2}{*}{$\begin{array}{l}\text { A weak motivation system, } \\
\text { without real animation and } \\
\text { evaluation culture }\end{array}$} & & $\begin{array}{l}\text { Problems for defining and animating } \\
\text { objectives }\end{array}$ \\
\hline & & $\begin{array}{l}\text { Quality performance and } \\
\text { audited progress not }\end{array}$ & & & $\begin{array}{l}\text { Information sharing issues between } \\
\text { divisions and service domains }\end{array}$ \\
\hline \multicolumn{3}{|c|}{ Interoperability issues } & \multicolumn{3}{|c|}{ Interoperability issues } \\
\hline \multicolumn{2}{|c|}{$\begin{array}{l}\text { Heterogeneous plants, heterogeneous } \\
\text { practices and processes, difficult } \\
\text { communication in managerial matrix } \\
\text { structure }\end{array}$} & $\begin{array}{l}\text { Missing standardization } \\
\text { and continuous } \\
\text { improvement of methods }\end{array}$ & \multicolumn{2}{|c|}{$\begin{array}{l}\text { a few standardized methods, difficult } \\
\text { communication between functional networks } \\
\text { and with external partners }\end{array}$} & $\begin{array}{l}\text { Heterogeneous service missions, no } \\
\text { coordination between them }\end{array}$ \\
\hline
\end{tabular}

Fig.1: Analysis of interoperability issues in Valeo group and CG84 


\section{Interoperability design approaches}

Systems, as software, process or organization, are not originally interoperable, excepted when they were originally designed as open systems (i.e. quite "universal" solutions, able to be plugged and played with any other system).

It seems therefore necessary that some approaches are required to increase systems interoperability [7]. One of these approaches is focused on the way to design interoperability [8]. As Fig.2 outlines, it is composed of three levels of abstraction, from a specific view to a generic standpoint:

- Good practices / Good solutions: Good practices are approaches that have been implemented and used in industries while good solutions are those developed as research results and there is not yet real implementation in the companies.

- Design patterns: they can be seen as proven solutions to a problem in a given context. They are also ways to describe best practices and good solutions, and to capture experience in a way that it is possible for others to reuse this experience.

- Design principles: design principles can be defined as a fundamental truth which stands for evidence, and is used as rules to follow to orient design decision-making.

This design approach proposes therefore a "process" to transform a heterogeneous organization into an interoperable system. It generalizes and diffuses broadly the best practices and the accurate solutions, by using patterns or principles.

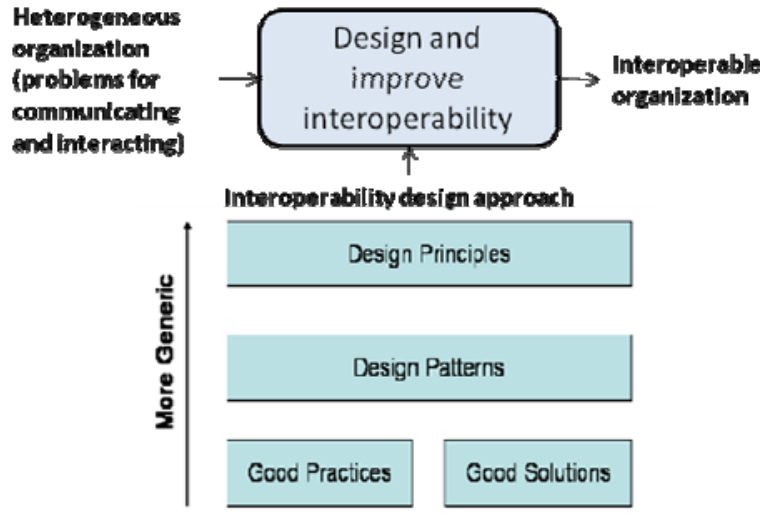

Fig.1: Abstraction levels for designing interoperability [8]

On the particular organizational interoperability challenge, some design principles have been already established. As described by Vallespir [9], two solutions appear: the standardization and the mutual adjustment between practices and processes.
The first one aims at defining standard practices and implementing them everywhere. Thus each enterprise or each business unit has to comply with these standardized best practices (Fig.3).

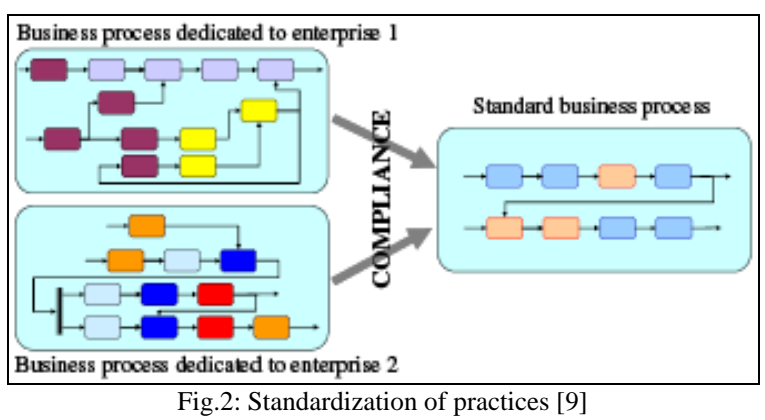

The other one proposes the mediation of practices coming from different organizational units. Each entity conserves therefore its specificities. Nevertheless, it has to "translate" its working standards and process modeling, so as to be understandable by and interoperable with others (Fig.4).

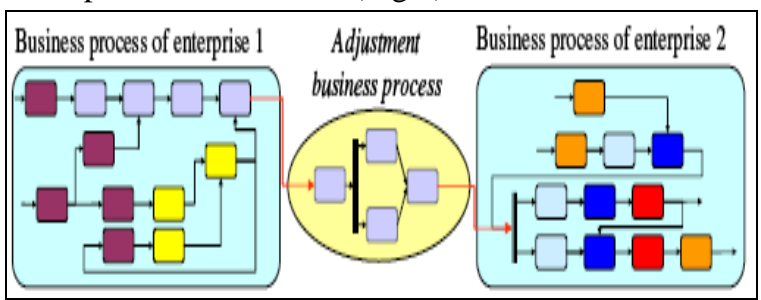

Fig.4: Adjustment of practices [9]

Thus cases study and literature identified organizational interoperability challenges. Then interoperability design approaches were explained. The following section is now describing a framework able to design and manage this organizational interoperability in enterprises.

\section{Organizational capability and 5 steps ${ }^{\circledR}$ framework for interoperability design and management}

Sharing good practices and processes can improve organizational interoperability, as mentioned in §3, either by standardization, either by adjustment.

However, how can a system be driven towards interoperability? How can these good practices be diffused, with which patterns?

A possible answer is organizational learning. Indeed, management of functional progresses and diffusion of good practices on all concerned entities should be able to raise enterprise interoperability.

This section presents 5Steps ${ }^{\circledR}$, a framework developing and managing organizational capabilities. First organizational capability is defined. It is the key 
concept of 5Steps ${ }^{\circledR}$, and it makes organizational learning processes actionable. Then the mechanisms of this framework are given. They enable the modeling of captured good practices and solutions around capabilities, and their diffusion throughout organization. Finally all these features are analyzed in an organizational interoperability standpoint, and their abilities for helping interoperability design and management are discussed.

\subsection{The concept of organizational capability}

According to Renard and Gilles Saint-Amant [6] and Ibrahima Fall [10] organizational capability can be defined as a "know how to act", a potential of action, resulting from the combination and the coordination of "action levers" (resources, knowledge and competencies) of the organization. This potential can be mobilized through the value flow of the company to perform a specific objective.

Several characteristics emerge from this concept:

- like knowledge, capability is systemic [11], i.e. it is broader than the sum of its components.

- An organizational capability cannot be considered separately from the "action process" [12, 13]. It constitutes a relevant unit of analysis (the action is indicative of the expression of the capability).

- Finally its behaviour is adaptive and linked to its "path dependency". This means that any capability is the product of a previous capability, and is the result of an active learning, both on individual and organizational levels [14, 13].

All these elements are summed up on Fig.5.

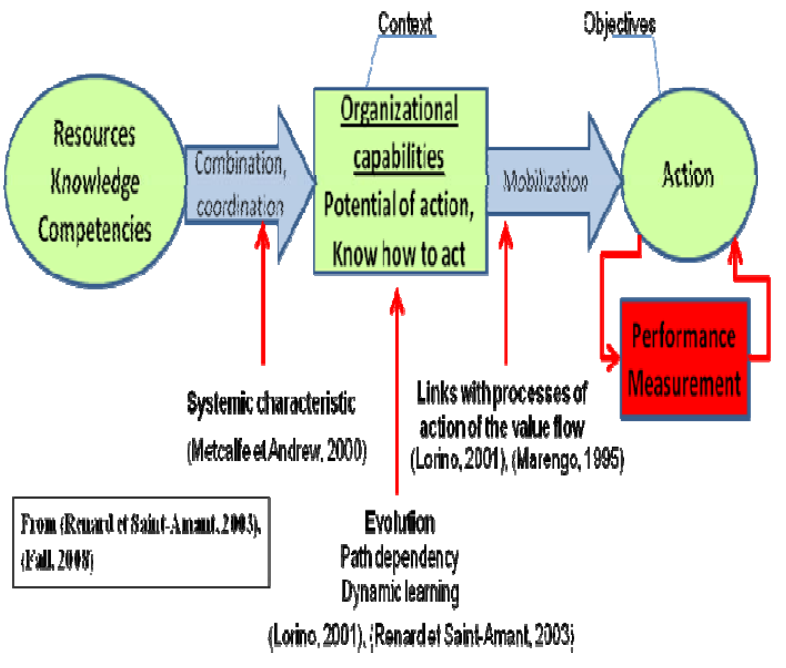

Fig.5. Organizational capability definition
The study will now focus on a framework enabling to model capabilities and their progress, and then to deploy and to manage them.

\subsection{Steps ${ }^{\circledR}$ Roadmapping}

5Steps ${ }^{\circledR}$ [5] is a framework developed by Valeo and MNM Consulting three years ago. Supported by a formalism, the roadmaps, and a software tool, it is now implemented on the whole Valeo Group. It is used to diffuse best practices, to integrate new sites, and to ease interactions between heterogeneous entities.

Moreover, the research and development works around this framework occur in the framework of Pilot2.0, supported by the French National Agency for Research (ANR) since December 2007.

4.2.1. Capturing and modeling functional domains with roadmaps. 5 Steps ${ }^{\circledR}$ puts organizational capability in the core structure of its performancedriven system, as shown in Fig.6. The roadmap structure uses the bases of organizational capabilities, by crossing in a matrix form "action levers" and the "path dependency" (figured by the maturity levels).

\begin{tabular}{|c|c|c|}
\hline \multirow{2}{*}{\multicolumn{2}{|c|}{$\begin{array}{l}\text { ROADMAP FORMALISM } \\
\text { AROUND THE CONCEPT OF } \\
\text { ORGANIZATION CAPABILITY }\end{array}$}} & $\begin{array}{c}\text { ROADMAP'S SUBJECT } \\
\text { Specific organizational capability to be developed }\end{array}$ \\
\hline & & LEVEL OF MATURITY OF THE ROADMAP \\
\hline \multirow{2}{*}{$\begin{array}{l}\text { ROADMAP'S } \\
\text { LEVERS OF } \\
\text { ACTION }\end{array}$} & $\begin{array}{l}\text { Components of } \\
\text { the capability } \\
\text { (resources, } \\
\text { knowledge, } \\
\text { competencies) }\end{array}$ & $\begin{array}{l}\text { PRIMARY REQUIREMENTS } \\
\text { Behaviour of the capability (set of events, set of } \\
\text { progress status) } \\
\text { Assessment of the capability's progress, i.e. the } \\
\text { status of the potentiality }\end{array}$ \\
\hline & $\begin{array}{l}\text { Activities } \\
\text { supporting the } \\
\text { capability's } \\
\text { development }\end{array}$ & $\begin{array}{c}\text { SECONDARY REQUIREMENTS } \\
\text { Assessment of activities supporting the capability } \\
\text { development }\end{array}$ \\
\hline $\begin{array}{l}\text { ROADMAP'S } \\
\text { CONTROLLING } \\
\text { ELEMENTS }\end{array}$ & $\begin{array}{l}\text { Performance of } \\
\text { the capability }\end{array}$ & $\begin{array}{l}\text { PERFORMANCE INDICATORS } \\
\text { Assessment of the expression of the capability, } \\
\text { throughout actions in value flow }\end{array}$ \\
\hline
\end{tabular}

Fig.6. Roadmap and organizational capability

The writing of roadmaps is based on the capture of good practices and good solutions. For instance, at Valeo, the good practices are identified and gathered by quality managers and auditors, or during exchanges between operational and functional managers. In parallel good solutions can be also proposed by functional experts to introduce new standards. Then 
capabilities development is modeled by roadmaps. Roadmaps' writers use the content of this repository which can be reused everywhere according to subjects of capability to develop.

For example, a roadmap for developing the capacity of managing Information Systems in plants was used and implemented in Valeo (cf. Fig.7).

4.2.2. Diffusing and measuring roadmaps. 5 Steps ${ }^{\circledR}$ also proposes a solution to manage these roadmaps. Thus roadmaps implementation, animation and evaluation behave the following scheme:

As the model emphasizes (Fig.8):

- Roadmap subjects are generated by strategic managers, who identify the interoperability key issues to be solved.

- The roadmaps are then written by functional managers, who organize capabilities following the maturity path of roadmaps. For this purpose they gather best practices and propose good solutions which improve organizational interoperability.

- These roadmaps are transmitted to middle and operational managers, who discuss objectives, in terms of level to reach and delay to respect for level achievement. This step is focused on the choice of organizational units which will have to implement roadmaps. Moreover, this deployment phase is looking for homogeneity, since roadmaps are diffused broadly. For instance, Valeo group modelled 40 roadmaps of 6 different functional networks that it deployed on 210

\begin{tabular}{|c|c|c|c|c|c|}
\hline $\begin{array}{l}\text { Actions } \\
\text { levers }\end{array}$ & 1 & 2 & 3 & 4 & 5 \\
\hline Manager & $\begin{array}{l}\text { A manager is } \\
\text { appointed }\end{array}$ & $\begin{array}{l}\text { Resources and } \\
\text { organization are } \\
\text { ready to go }\end{array}$ & $\begin{array}{l}\text { Management by } \\
\text { objectives is } \\
\text { implemented }\end{array}$ & $\begin{array}{l}\text { IS objectives } \\
\text { are aligned with } \\
\text { objectives of } \\
\text { other functional } \\
\text { networks }\end{array}$ & $\begin{array}{l}\text { IS department } \\
\text { is an internal } \\
\text { training school }\end{array}$ \\
\hline $\begin{array}{c}\text { Data and } \\
\text { applications }\end{array}$ & $\begin{array}{l}\text { Applications } \\
\text { comply with local } \\
\text { laws }\end{array}$ & $\begin{array}{l}\text { A fulfilled } \\
\text { cartography } \\
\text { exists }\end{array}$ & $\begin{array}{l}\text { IS is an actor } \\
\text { among all the } \\
\text { stage of } \\
\text { applications } \\
\text { lifecycle }\end{array}$ & $\begin{array}{l}\text { Data Quality } \\
\text { process is } \\
\text { implemented }\end{array}$ & $\begin{array}{l}\text { Data complies } \\
\text { with last } \\
\text { standards }\end{array}$ \\
\hline Suppliers & $\begin{array}{l}\text { Purchasing } \\
\text { processes are } \\
\text { defined and } \\
\text { implemented }\end{array}$ & $\begin{array}{l}\text { IS Purchases } \\
\text { comply with } \\
\text { standard } \\
\text { processes }\end{array}$ & $\begin{array}{l}\text { Contracts are } \\
\text { organized based } \\
\text { on deliverables }\end{array}$ & $\begin{array}{l}\text { Suppliers audit } \\
\text { gives } \\
\text { performance } \\
\text { indicators }\end{array}$ & $\begin{array}{l}\text { Suppliers are } \\
\text { involved in a } \\
\text { continuous } \\
\text { improvement }\end{array}$ \\
\hline
\end{tabular}

Fig.7. Valeo Roadmap on IS management capability sites (a site is a production place for on products, a plant able to produce several products). It aims at sharing and making the same standards actionable on all organizational entities.

- Roadmaps are implemented, with the support of a software application which ensures the broad diffusion and enables a self-assessment of deliverables to achieve.

- Roadmap measurement by self-assessment provides some reporting on progress states and some feedbacks for improving roadmap's content. The selfassessment is also reported into scorecards. These data are audited regularly, and become inputs of a Business Intelligence tool (like for instance at Valeo). Measures aggregation and consolidation allow monitoring capabilities progress. The progress status can be compared between organizational entities, giving a clear view of maturity of organizational capabilities among several plants, products branches, functional divisions...

- Finally, in a process of continuous improvement, feedbacks are collected about the content and the deployment of roadmaps. New versions of roadmaps can be proposed, to upgrade these interoperability design patterns. Thus, 5 Steps ${ }^{\circledR}$ framework proposes a model to continuously increase interoperability design, by taking account of problems met by operational people and by consequently improving the patterns.

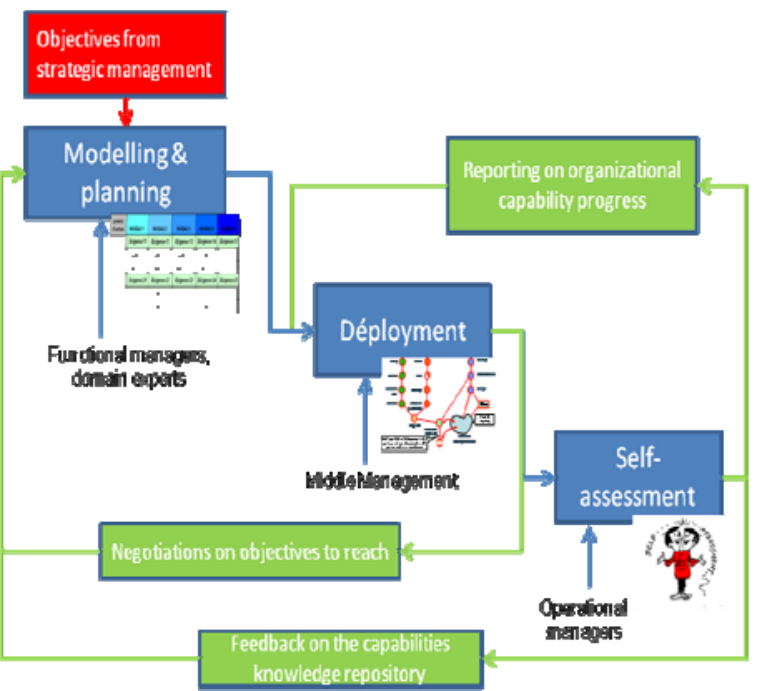

Fig.8. Deployment model for managing organizational interoperability [from 5] 
4.2.3. Designing and managing interoperability with organizational capability and roadmapping. As emphasized in its definition (cf. §4.1), organizational capability results from the coordination and the interactions of "action levers", and is the product of an organizational learning process (path dependency). Capability is therefore a progressive learning way to make a set of resources, knowledge and competencies interoperable, in order to use them to achieve a specific objective.

On another hand, a roadmap aims at managing an organizational capability, i.e. several resources, as manager, applications and suppliers, in order to improve their coordination and their communication. The progressive combination of these resources therefore enables to acquire a collective capability, and to develop their interoperability. Thus roadmaps are interoperability “design pattern” (cf. §3), which transform "good practices" and "good solutions" in a model implementable everywhere.

Thus roadmapping can constitute a support for designing organizational interoperability, by following the three abstraction levels of interoperability design approaches presented in §3 (cf. Fig.9):

- Good practices are collected on operational ground, and good solutions are proposed by functional experts of organizations.

- From this collection, roadmaps are modeled, providing “interoperability design patterns" for organizations.

- Finally, the management method and the tool supporting it give some rules to diffuse, implement, measure and improve these interoperability patterns, as a kind of "design principles".

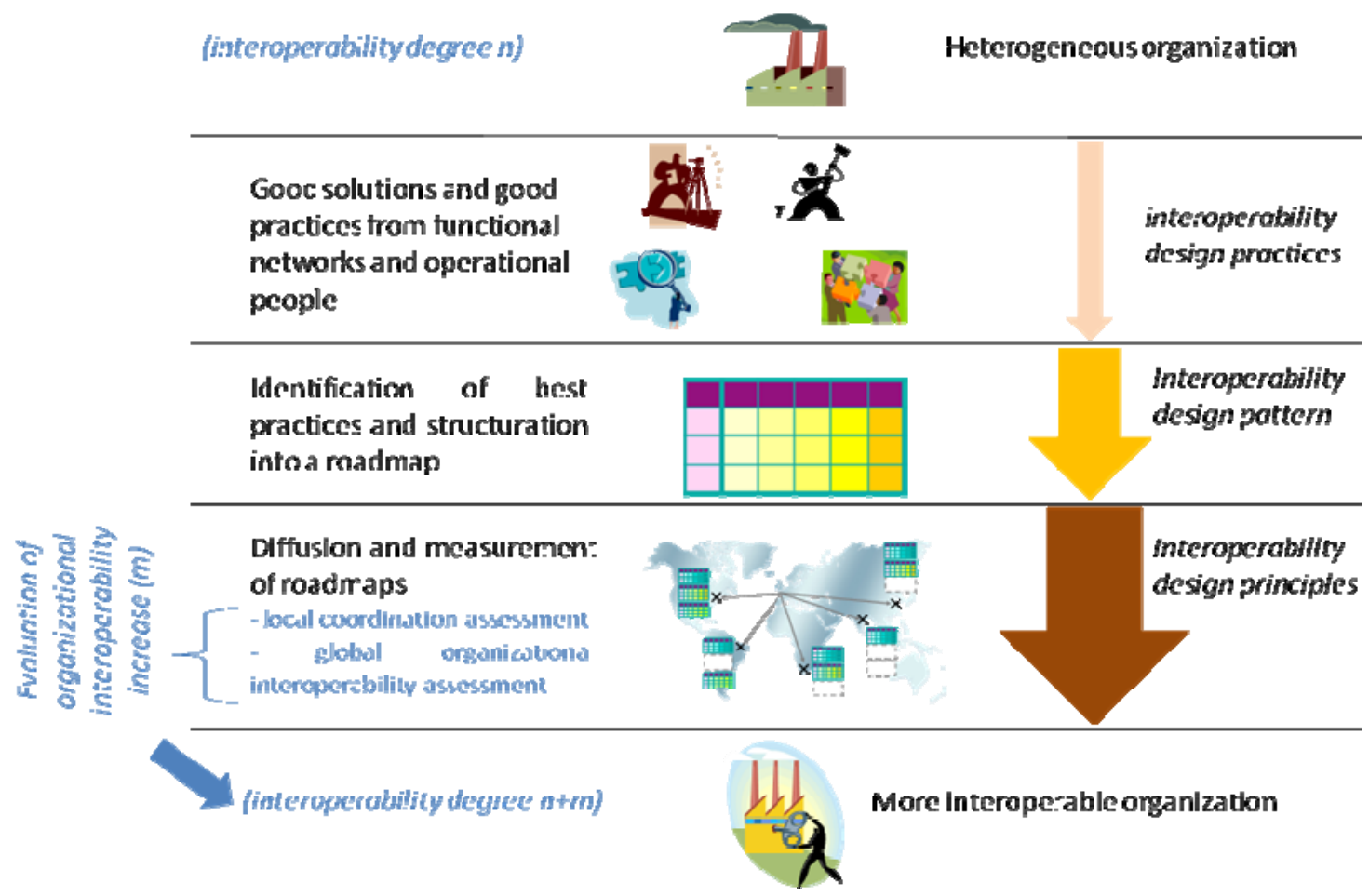

Fig.9. Model of organizational interoperability design and management with roadmaps

Moreover the roadmapping measurement system provides a new means to assess the interoperability degree of an organization at two levels of precision:

- the local roadmap assessment indicates for each site how resources are coordinated so as to perform the organizational objectives.

- the consolidation and the comparison of different roadmaps indicates how plants, how business units are interoperable in order to provide the same results with the same quality level.

These indicators could therefore represent how much an organization increased its interoperability, and which efforts it has to continue to improve this interoperability. 


\section{Discussion}

This paper presents organizational capability and roadmapping as tools for helping the design and the management of organizational interoperability:

- practices could be standardized and harmonized, and all organizational entities follow the same way to reach the same interoperability level.

- Semantic interoperability is also improved, Indeed roadmaps can be viewed as such “ontologies” [15, 16], by giving a shared and unique description of a functional domain and their development.

- Roadmap measurement can provide new indicators on local coordination of resources and global interoperability of plants, business units...

These elements have seemingly positive impacts where they have been implemented. Thus a survey within the Valeo Group [17] shows that $74 \%$ of managers using this formalim consider that the roadmapping framework makes explicit and accessible the best practices repositories. Moreover, for $80 \%$ of middle management and $75 \%$ of operational people, it incites communication and information sharing between plants.

However some limits also appeared in the implementation of the roadmapping:

- The roadmap structure introduces some new heterogeneity problems: this one aims at increasing organizational interoperability by driving and coordinating several « levers", but getting resources working together can oppositely trigger off such a complexity and therefore a bigger risk of heterogeneity.

- Roadmapping is based on a standardization of practices, and can therefore be too « normative ». Even if communication and interactions are improved by the use of these actionable design patterns, each actor observes a limitation of her/his autonomy about his/her way of working and achieving his/her tasks. It is why some negotiation and collaboration loops are planned in the method, but they must be bettered up.

For this last purpose, a current work is made to better adapt these generic roadmaps to the heterogeneity of organizations. It is based on the identification and the determination of some groups of specificities. For instance, a roadmap concerns with only a functional domain. However, some disparities can appear in its deployment, according to some cultural or historical criteria (which bring about some difficulties for understand or have the means to implement the roadmap). To solve this issue, feedbacks must be of course collected and organized.

But self-assessment data can also be analyzed to provide further information, in order to identify a singularity in roadmap deployment on a site, and to find the cause of this singularity (cf. Fig.10).

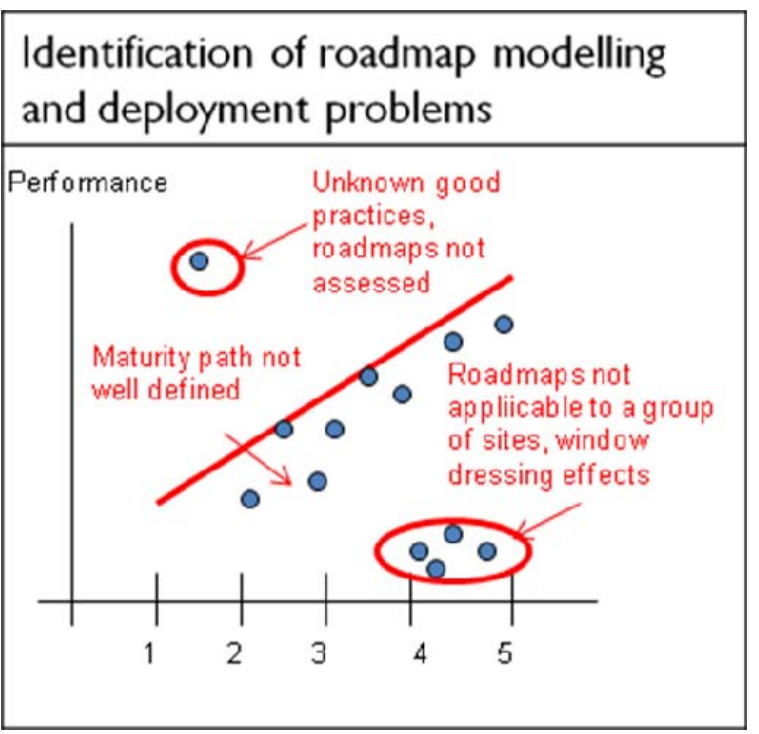

Fig.10. Roadmap’s improvement perspectives

\section{Conclusion}

This part emphasized that organizations can be driven towards interoperability with the support of organizational learning processes.

Organizational capabilities and roadmaps provide solutions to design and manage this interoperability development, based on two distinct levels:

- At a first stage, organizational capability constitutes a design pattern, which allows combining different "action levers" and driving them on the road towards interoperability. Thus organizational knowledge and synergy are improved [18].

- At a second stage, roadmaps enable to implement these set of best practices as "interoperability patterns", giving some rules for the animation and the control of interoperability management.

Nevertheless the current implementation ofpresented concepts and framework results rather in a "standardization of practices", as defined by Vallespir in §3. It is why the future works will look for turning the current system into a more flexible system taking account of some adjustment, e.g. by determining some groups of specificities for the deployment of roadmaps. 


\section{Acknowledgement}

Authors acknowledge the French National Agency of Research (ANR), which supports and funds Pilot2.0 project and the current research works. It involves laboratories (IRCCyN and M-LAB), companies (MNM Consulting, Valeo) and institutional partners (General Council of Vaucluse). The aim of this partnership is to provide a generic method, to improve existing tools and to deploy them on other types of organizational structures.

\section{References}

[1] ATHENA, "Description of work", sixth framework program, European Integrated Project ATHENA, 2003

[2] Vernadat, F.B., Interoperable enterprise systems: Principles, concepts, and methods, Annual Review in Control, 2007

[3] Blanc, S., Ducq, Y., Vallespir, B. Evolution management towards interoperable supply chains using performance measurement, Computers in Industry, 2007

[4] ANR, Report on selected projects for Software Technology Programm, 2007 http://www.agence-nationalerecherche.fr/documents/aap/2007/selection/Techlog-2007.pdf [5] Monomakhoff, N., Blanc, F., La méthode 5Steps ${ }^{\circledR}$ : Pour déployer efficacement une stratégie, AFNOR, 2008

[6] Renard, L. et Saint Amant, G., Capacité, capacité organisationnelle et capacité dynamique : une proposition de définitions, Les cahiers du Management Technologique, 2003, p.43-56

[7] INTEROP NoE, Practices, principles and patterns for interoperability, Deliverable D6.1, 2005

[8] Chen D., Doumeingts G., Vernadat F., Architectures for enterprise integration and interoperability: Past, present and future, Computer in Industry, 2008

[9] Vallespir, B., Chapurlat, V., Enterprise modelling and verification approach for characterizing and checking organizational interoperability, ETFA, 2007

[10] Fall, I., La capacité comme objet de gestion : genèse, mode d'emploi et enjeux à travers une expérience pionnière de mise en gestion systématique des capacités organisationnelles, ACFAS $-4^{\mathrm{e}}$ rencontre, 2008

[11] Metcalfe, S.J., Andrew J., Knowledge and capabilities: Resources, Technology and Strategy. 2000

[12] Marengo, L., Apprentissage, compétences et coordination dans les organisations, Economica, Paris, 1995

[13] Lorino, P. Méthodes et Pratiques de la Performance, Editions d'Organisation, Paris, 2001

[14] Saint Amant, G., Développement des capacités organisationnelles : une démarche, 2003

[15] Gruber T. What is an Ontology? Summary statement of Gruber's defintion of ontology, 2001

[16] Perry N., Bernard A., Candlot A., Ammar Khodja S., High-value document generation: an ontology based methodology proposal, in Conference on Advanced Information Systems Engineering, Porto, Portugal, 2005
[17] Fall, I., Rauffet, P., Study of impacts of organizational capabilities management and roadmapping use at Valeo Group, internal resource from MNM Consulting, 2008

[18] Candlot A., Du Preez N., Bernard A., Synergy and Knowledge in an Innovative Project between Academia and Industry, International Conference on Competitive Manufacturing, Stellenbosch, 2004 